\title{
Inflation, Price Dispersion and Market I ntegration through the Lens of a Monetary Search Model
}

Sascha S. Becker* Dieter Nautz*

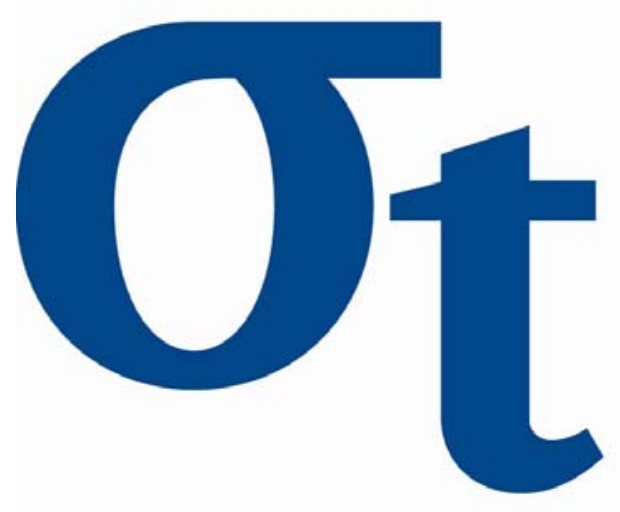

* Freie Universität Berlin, Germany 


\title{
Inflation, Price Dispersion and Market Integration through the Lens of a Monetary Search Model
}

\author{
Sascha S. Becker and Dieter Nautz * \\ Department of Economics \\ Free University Berlin
}

November 23, 2010

\begin{abstract}
Monetary search theory implies that the real effects of inflation via its impact on price dispersion depend on the level of search costs and, thus, on the level of market integration. For less integrated markets, the inflation-price dispersion nexus is predicted to be asymmetrically V-shaped which results in an optimal inflation rate above zero. For highly integrated markets with low search costs, however, the impact of inflation on price dispersion should only be small. Using price data of the European Union member states, this paper is the first that tests and confirms these predictions of monetary search theory.
\end{abstract}

Keywords: Inflation; Relative price variability; Monetary search; Market integration.

JEL classification: C23, D40, E31, F40

\footnotetext{
*This research was supported by the Deutsche Forschungsgemeinschaft through the CRC 649 "Economic Risk". We thank Aleksander Berentsen, Jörg Breitung, participants at the 2010 annual meeting of the European Economic Association, the 2009 annual Congress of the Verein für Socialpolitik and the 2009 Macroeconometric Workshop of the German Institute of Economic Research for helpful comments and suggestions. Financial support by the Monetary Stability Foundation is gratefully acknowledged. E-mail: sascha.becker@fu-berlin.de; dieter.nautz@fu-berlin.de.
} 


\section{Introduction}

In macroeconomic theory, the impact of inflation on price dispersion is a major channel of real effects of inflation. According to menu-cost (Rotemberg, 1983) or Lucas-type misperception models (Barro, 1976) inflation increases relative price variability (RPV), distorts the information content of prices, and, thereby, impedes the efficient allocation of resources. Both types of models imply a monotonous inflation-RPV relationship in which inflation always lowers welfare. As a consequence, the early empirical evidence is typically based on linear regressions of RPV on the rate of inflation (see e.g. Debelle and Lamont, 1997, and Jaramillo, 1999).

Recent monetary search models predict that the impact of inflation on price dispersion and welfare is more complex. In particular, Head and Kumar (2005) show that both the inflation-RPV and the inflation-welfare nexus are V-shaped implying that the optimal rate of inflation is above zero. This paper uses the Head and Kumar (2005) framework to shed more light on the functional relationship between inflation and RPV. Solving the monetary search model numerically reveals two further implications. Firstly, RPV should react stronger to inflation when inflation is low. Secondly, when search costs decrease, the curvature of the asymmetrically V-shaped inflation-RPV relationship flattens and price dispersion responds less to inflation. So far, these implications for the inflation-RPV nexus have not been tested empirically. Assuming that search costs decrease when markets become more integrated, the empirical part of the paper fills this gap by estimating the relationship between inflation and RPV for sub-groups of European countries with different degrees of goods market integration.

Contradicting the predictions of standard menu-cost or misperception models, recent empirical evidence suggests that the relation between inflation and RPV is non-linear, see e.g. Fielding and Mizen (2008), Bick and Nautz (2008), and Choi (2010). A first attempt to explicitly test the implications of the Head and Kumar (2005) model is given by Caglayan et al. (2008). Using price observations from bazaars, convenience stores, 
and supermarkets in Turkey, they find a symmetric V-shaped relationship between inflation and RPV, but do not explore the role of market integration.

Monetary search models are designed for countries with low or moderate inflation rates (see Head and Kumar, 2005, p.535). Therefore, members of the European Union (EU) are natural candidates for an empirical test of these models. Although European integration has made considerably progress on average, notable differences in goods market integration across Europe have remained. The following analysis compares two groups of countries. The first group contains the highly integrated Euro-area countries where a common currency contributes to keep search costs low. The second group contains the rather heterogenous group of all $27 \mathrm{EU}$ member states where markets are less integrated and, thus, search costs should be significantly higher compared to Euro-area countries, see Engel and Rogers (2004) and Parsley and Wei (2008).

Our empirical results show that the impact of inflation on price dispersion is nonlinear and crucially depends on the level of goods market integration. In particular, the evidence supports both predictions of the monetary search model. On the one hand, the empirical relation between inflation and price dispersion is asymmetrically V-shaped in the less integrated EU-27 economy suggesting an optimal annual inflation rate of about 3\%. On the other hand, the impact of inflation on price dispersion is only small and insignificant for the highly integrated Euro-area markets where search costs are low.

The paper is organized as follows. Section 2 briefly reviews the Head and Kumar (2005) monetary search model and derives testable implications for the empirical relationship between inflation and RPV. Section 3 introduces the data and specifies the price variability and inflation measures. Section 4 presents the empirical results obtained for the inflation-RPV nexus of the EU27 and the Euro-area countries. Section 5 investigates the inflation-RPV nexus accounting for important policy events that may have increased European market integration over time. Specifically, we consider the 
effects of the introduction of the Euro as a physical currency in 2002 and the role of the EU enlargement in 2004 for the empirical inflation-RPV relationship. Section 6 offers some concluding remarks.

\section{The Monetary Search Model}

\subsection{Inflation, Price Dispersion and Welfare}

The Head and Kumar (2005) monetary search model emphasizes that buyers have only incomplete information about the prices offered by different sellers 1 In this model, the impact of inflation on price dispersion and welfare is determined by two opposing effects. On the one hand, higher expected inflation lowers the value of fiat money, which increases demand for goods and, thereby, sellers' market power. Since market power differs across sellers, higher expected inflation leads to higher price dispersion. On the other hand, higher expected inflation also raises the gains of search which adds two further dimensions to its effect on welfare. First, the search induced by inflation is costly. And second, because it induces search, inflation increases buyers' information and, thereby, weakens sellers' market power. Therefore, inflation may have also welfare-improving effects by reducing the dispersion of prices. As a result, the sign of the overall effect of inflation on price dispersion and welfare depends on the level of inflation.

In the following, we derive two further theoretical implications on the functional relationship between inflation and price dispersion by solving the monetary search model numerically for a plausible set of parameter values typically used in calibrated macroeconomic models, see Head and Kumar (2005) and Head et al. (2010). It is worth

\footnotetext{
${ }^{1}$ Adopting the monetary exchange framework proposed by Shi (1999), Head and Kumar (2005) extend the nonsequential price setting model of Burdett and Judd (1983) in order to link inflation and the optimal search strategy. Head et al. (2010) establish a stochastic version of the Head and Kumar (2005) model to study the extent of real and nominal price adjustments to fluctuations in productivity and the inflation rate.
} 
emphasizing that both results hold for a very broad range of parameter values, see Appendix A1 for a more detailed presentation of the model and the simulation exercise.

Figure 1: Inflation, price dispersion, and welfare

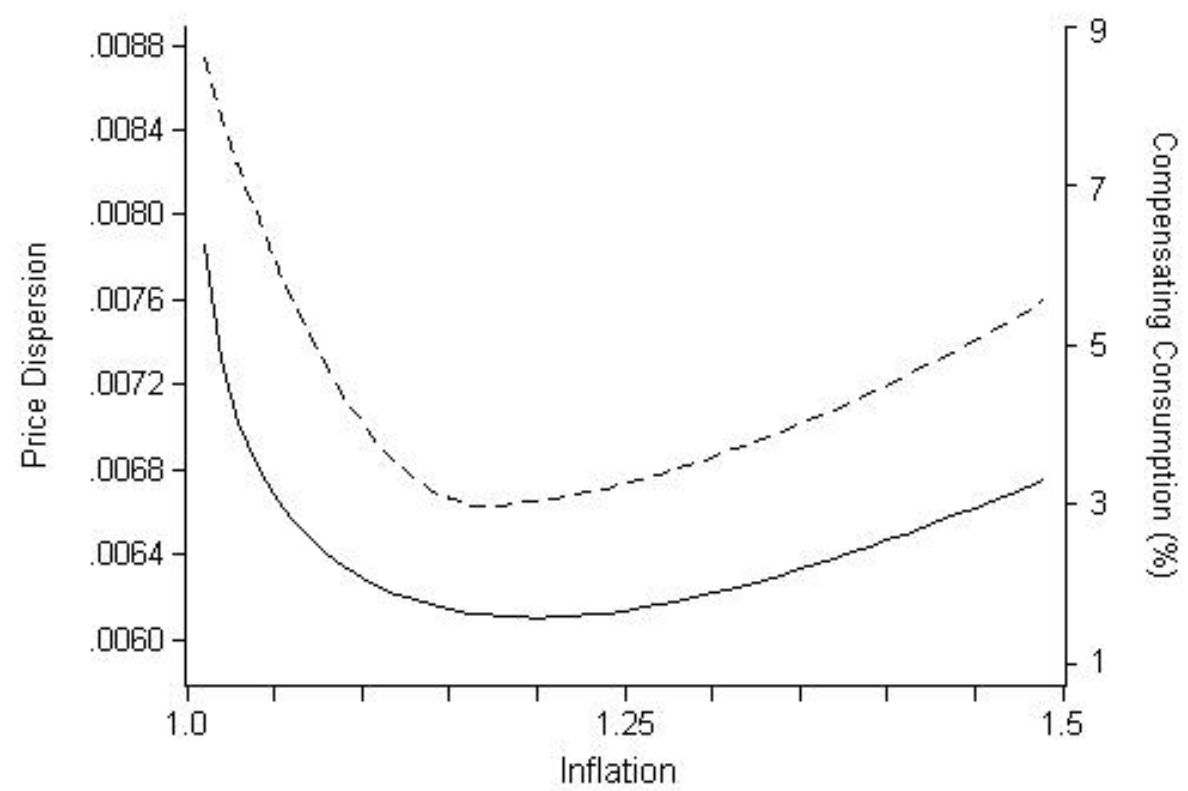

Notes: The figure shows the impact of expected inflation on price dispersion and welfare as predicted by the Head and Kumar (2005) monetary search model. Price Dispersion (solid line - left scale); Compensating Consumption (\%) (dashed line - right scale). For more details, see Appendix A1.

Figure 1 displays the benchmark simulation for inflation's impact on welfare and price dispersion. The welfare cost of inflation is measured by the quantity of consumption required to give a representative household the same utility as she would receive in the optimum (without asymmetric information) as a percentage of optimum consumption. ${ }^{2}$ The figure shows that at low inflation rates the reduction of market power resulting from increased search intensity in response to an increase in inflation is sufficient to decrease price dispersion and to raise welfare (i.e. welfare costs decrease). However, when inflation exceeds a critical value, the welfare distorting effect of infla-

\footnotetext{
${ }^{2}$ Craig and Rocheteau (2008) relate the measure of the welfare cost of inflation obtained from a monetary search model to the traditional measures based on the "welfare triangle" methodology of Lucas (2000).
} 
tion eventually dominates.

As a result, the relationship between expected inflation and price dispersion can be captured by a V-shaped specification where the vertex occurs at positive levels of inflation. Note that the welfare maximizing inflation rate $\Pi^{*}$, which is determined by the minimum of the welfare cost curve, is positive and located below but very close to the vertex of the inflation-RPV nexus. Accordingly, this vertex may serve as a proxy for $\Pi^{*}$.

Figure 1 further shows that the relationship between inflation and price dispersion is asymmetric. The economics behind this asymmetry can be explained as follows. At low levels of inflation, a relatively large fraction of buyers observe only a single price. In this situation, an increase in inflation induces strong increases in buyers' search intensity in order to avoid inflation-induced increases of seller's market power. Accordingly, changes in inflation have relatively large effects on search intensity and, thereby, on price dispersion. As the rate of inflation rises, the share of buyers observing only one price decreases. Therefore, any further increase in inflation has a smaller effect on search intensity and price dispersion.

In the appendix, we show that asymmetrically V-shaped effects of inflation require that search costs are sufficiently high. Since the level of search costs should be negatively related to the degree of market integration, this leads to our first empirically testable implication of the monetary search model:

Hypothesis 1: Consider the monetary search model of Head and Kumar (2005). Provided that the degree of market integration in an economy is sufficiently low, i.e. search costs are sufficiently high, the relationship between expected inflation and RPV is asymmetrically $V$ shaped with a non-zero optimal rate of inflation.

A first attempt to test this hypothesis is given by Caglayan et al. (2008) who found, however, a symmetric V-shaped relationship between price dispersion and expected inflation in Turkey. 


\subsection{Search Costs and Market Integration}

In the benchmark simulation presented above, search costs have been calibrated to achieve an average mark-up of prices over marginal costs of $10 \%$, compare Gali et al. (2001) and Head et al. (2010). However, due to the ongoing market integration in Europe, mark-ups may have declined over the recent years.

Figure 2: The inflation-RPV nexus and the role of search costs

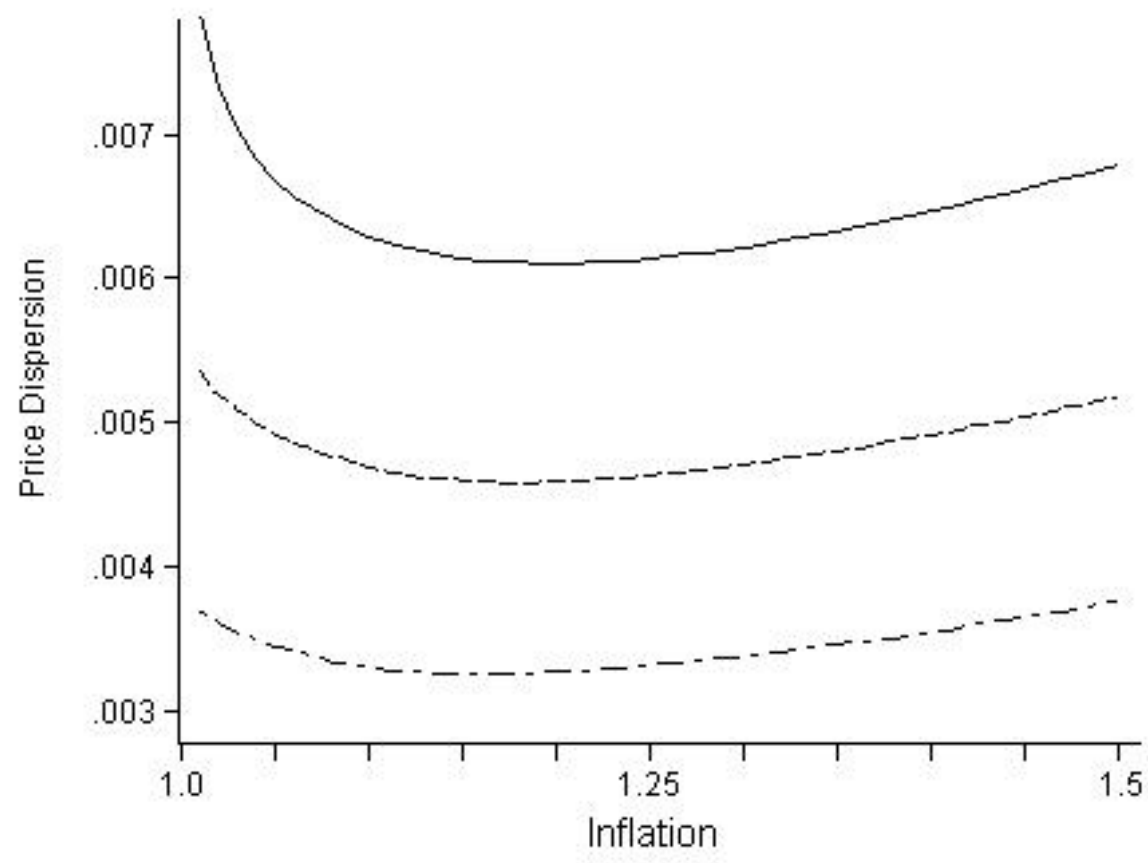

Notes: Figure plots price dispersion versus inflation for varying levels of search costs: i) high search costs (upper graph) ii) moderate search costs (middle graph) and iii) low search costs (lower graph). See Appendix A1 and Figure 1 for more details.

To shed more light on the role of search costs for the real effects of inflation, we computed additional model simulations with varying levels of search costs. The upper graph in Figure 2 displays the asymmetric V-shaped relationship between inflation and RPV for the benchmark simulation where search costs are high. The two remaining graphs present simulation results for moderate and low search costs, respectively. Compared to the benchmark, decreasing search costs shift the inflation-RPV nexus 
downwards. More importantly, the curvature of the relationship gets progressively flatter: With lower search costs the proportion of buyers observing only one price quote decreases. Therefore, an increase in inflation has a smaller impact on search intensity and price dispersion responds less to inflation.

We summarize this implication of the Head and Kumar (2005) monetary search model as follows:

Hypothesis 2: With increasing market integration, i.e. decreasing search costs, the $V$ shaped relationship between expected inflation and RPV gets progressively flatter and the impact of inflation on the dispersion of prices declines.

In the limiting case, when search costs are zero, inflation has no impact on price dispersion $?^{3}$

\subsection{Market Integration in the European Union}

According to the predictions of Head and Kumar (2005) and the hypotheses stated above, market integration crucially affects the relationship between inflation and price dispersion. In the following, both hypotheses will be tested using panel data from two subgroups of EU member states characterized by different levels of market integration.

For Euro-area countries, on the one hand, much progress on the issue of market integration and price transparency has been made with the Single Market Program of 1992 and the introduction of the Euro in 1999. Using price data across different Euro-area countries, Engel and Rogers (2004) find evidence for an advanced integration of Eurozone consumer markets caused by the efforts to reduce economic barriers initiated in the 1990s. Parsley and Wei (2008) show that market integration among the countries

\footnotetext{
${ }^{3}$ When search costs fall below a critical threshold value, all buyers optimally observe more than one price quote. The only possible price distribution is then concentrated at the marginal cost price and price dispersion equals zero. Accordingly, if search costs are extremely low, the distorting effect of inflation on price dispersion vanishes and the classical dichotomy holds.
} 
in the Eurozone is uniformly higher compared to non-Euro countries. Therefore, the Euro-area should represent a highly integrated market where search costs are low. On the other hand, the EU 27 economy consists of a very heterogeneous group of countries and exhibits a lower degree of market integration $4^{4}$

\section{Data and Measurement}

Many empirical contributions analyze the impact of inflation on intermarket relative price variability (RPV), see e.g. Debelle and Lamont (1997), Jaramillo (1999), and Becker and Nautz (2009). Intermarket RPV is typically defined as the standard deviation of the rates of inflation of various products of goods and services around the average inflation rate in a given city or country. By contrast, the intramarket side (deviations of individual product specific inflation rates with respect to the product average inflation rate across cities or countries) seems to be underresearched.$^{5}$ In the following empirical study, the focus shall be on price variability in Europe within the intramarket side because search models are specifically designed to account for price dispersion within a given market.

We use monthly data for various subcategories of the Harmonized Index of Consumer Prices (HICP) provided by the Eurostat database. The data set runs from January 1996 to August 2008. It includes observations of the twelve major HICP subcategories for all 27 EU member states ${ }^{6}$ Following the empirical literature, intramarket relative price

\footnotetext{
${ }^{4}$ Austria, Belgium, Finland, France, Germany, Greece, Ireland, Italy, Luxembourg, Netherlands, Portugal and Spain are grouped together in Euro-area, whereas the EU-27 group consists of the Euro-area countries plus Bulgaria, Czech Republic, Denmark, Estonia, Cyprus, Latvia, Lithuania, Hungary, Malta, Poland, Romania, Slovenia, Slovakia, Sweden and United Kingdom. Although Slovenia, Cyprus and Malta adopted the Euro in 2007 and 2008, respectively, we do not include them into the Euro-area group, because our sample already starts in 1996. This implicates that Slovenia, Cyprus and Malta did not participate in the EMU for the major part of our sample period. Alternatively, one can split the countries into a Euro-area group and a non-Euro group. The qualitative results presented in this paper do not depend on this splitting scheme.

${ }^{5}$ Exceptions include Lach and Tsiddon (1992), Reinsdorf (1994), Parsley (1996), Fielding and Mizen (2000), and Caglayan et al. (2008).

${ }^{6}$ These HICP subcategories are: food and non-alcoholic beverages (CP01); alcoholic beverages, tobacco and narcotics (CP02); clothing and footwear (CP03); housing, water, electricity, gas and other fuels
} 
variability is defined as:

$$
R P V_{i t}=\left[\sum_{j=1}^{N} w_{j t}\left(\pi_{i j t}-\pi_{i t}\right)^{2}\right]^{0.5},
$$

where $\pi_{i j t}$ is the rate of change in the price index of the $i$ th subcategory in country $j$ at time period $t$ and $\pi_{i t}$ is the average rate of change in product category $i^{\prime}$ s price index $\left(\pi_{i t}=\sum_{j=1}^{N} w_{j t} \pi_{i j t}\right) . w_{j t}$ is the weight of country $j$ at time $t$ in the overall HICP index $\left(\sum_{j=1}^{N} w_{j t}=1\right)$ and $N$ refers to the number of countries under consideration.

Overall HICP inflation is denoted by $\Pi_{t}=\sum_{j=1}^{N} w_{j t} \Pi_{j t}$, where $\Pi_{j t}$ is overall inflation in country $j$ in time period $t$. Table 4 in Appendix A2 presents some summary statistics on the RPV and inflation measures, see also Figures 3 and 4. Panel Unit root tests indicate that all inflation and RPV measures are stationary 7

Theories on the relation between inflation and RPV emphasize the different roles of expected and unexpected inflation. In line with the empirical literature, we base our measures of expected inflation on a time series representation of inflation. Specifically, we estimate an AR(12) model for $\pi_{i t}$ and $\Pi_{t} 8$ Expected inflation is derived as the one period-ahead inflation forecast while unexpected inflation is the resulting forecast error. Note that beating the forecasting performance of univariate time series models of inflation is not an easy task, particularly over a monthly forecast horizon, see e.g. Elliott and Timmermann (2008).

(CP04); furnishing, household equipment and routine maintenance of the house (CP05); health (CP06); transport (CP07); communication (CP08); recreation and culture (CP09); education (CP10); restaurants and hotels (CP11); miscellaneous goods and services (CP12). Data series are seasonally adjusted using the Census X11 procedure.

${ }^{7}$ Results of the Panel Unit Root tests are not presented but are available on request.

${ }^{8}$ Additionally to the autoregressive parts, the $\pi_{i t}$ forecast model also contains past values of overall HICP inflation (up to 3 lags). 


\section{Inflation, Price Dispersion and the Role of Market Integra- tion}

\subsection{The Empirical Model}

This Section empirically tests implications of market integration on the inflation-RPV nexus derived from the Head and Kumar monetary search model. Since expected inflation in the Head and Kumar model stems from growth in the stock of fiat money, our analysis focuses on overall expected inflation $\left(\Pi^{e}\right)$. To control for the predictions of menu-cost and signal extraction models, we follow the empirical literature on the intramarket inflation-RPV relationship (see e.g. Lach and Tsiddon, 1992) and include the absolute values of expected $\left(\pi_{i}^{e}\right)$ and unexpected $\left(\pi_{i}-\pi_{i}^{e}\right)$ product specific inflation into our regression model. The panel equation contains a product fixed effect $\left(\alpha_{i}\right)$ and monthly time dummies $\left.\left(\lambda_{t}\right) \cdot\right\}^{9}$

$$
R P V_{i t}=\alpha_{i}+\lambda_{t}+\beta_{1}\left|\pi_{i t}^{e}\right|+\beta_{2}\left|\left(\pi_{i t}-\pi_{i t}^{e}\right)\right|+\beta_{3}\left|\Pi_{t}^{e}-a\right|+\beta_{4} D_{t}\left|\Pi_{t}^{e}-a\right|+\epsilon_{i t}
$$

According to Hypothesis 1, the relationship between overall expected inflation and price dispersion can be captured via a V-shaped specification where the vertex occurs at positive levels of expected HICP inflation. Following Caglayan et al. (2008), we therefore include $\left|\Pi_{t}^{e}-a\right|$ (with $a \geq 0$ ) into our regression model. For $a>0$ the vertex of the V-shaped inflation-RPV relation shifts away from the origin towards positive values of expected overall inflation. The equation is estimated by means of minimizing the sum of squared residuals using a grid search procedure for $a$

Hypothesis 1 furthermore states that the impact of expected inflation on RPV is asymmetric. The asymmetry is captured by the term $D_{t}\left|\Pi_{t}^{e}-a\right|$ where $D_{t}$ is a dummy

\footnotetext{
${ }^{9}$ Including lagged price dispersion or a measure of overall unexpected inflation $\left(\Pi-\Pi^{e}\right)$ to Equation (2) does not affect our results.

${ }^{10}$ The starting point of our grid search is $a=0$. Subsequently, we increase $a$ in increments of 0.00025 up to $a=0.0075$. Note that the average values of monthly overall inflation for our two country samples are 0.001723 and 0.002703 (0.021 and 0.032 in annual terms), respectively (see Table 4). So, $a=0.0075$ seems to be a reasonable endpoint.
} 
variable which equals one when $\Pi_{t}<a$ and zero otherwise. For levels of inflation below $a$ the slope of the V-shaped inflation-RPV nexus equals $\beta_{3}+\beta_{4}$, whereas for inflation rates above $a$ the marginal impact of inflation on RPV is given by $\beta_{3}$. Since theory predicts that the response of RPV to expected inflation is stronger for values of inflation below the vertex, we would expect $\beta_{4}$ to be greater than zero.

According to Hypothesis 2, higher market integration flattens the V-shaped relationship between inflation and RPV. We therefore expect that the size and significance of the estimated coefficients for $\beta_{3}$ and $\beta_{4}$ should decrease with the degree of market integration. Whereas both coefficients should be close to zero for highly integrated markets like the Euro-area, they should be positively signed and significant for less integrated markets like the EU27 economy.

\subsection{Inflation and Price Dispersion in a Less Integrated Market}

The estimation results for the EU 27 economy are shown in the first column of Table 1. In line with menu-cost and misperception models, we find a significant positive effect of expected and unexpected product specific inflation on price dispersion, i.e. $\widehat{\beta}_{1}, \widehat{\beta}_{2}>0$. More interestingly, however, for the huge, and probably less integrated EU 27 market both coefficients on overall inflation, $\widehat{\beta}_{3}$ and $\widehat{\beta}_{4}$, are highly significant and plausibly signed. The estimated vertex $a$ in the inflation-RPV nexus is greater than zero resulting in a right shift of the V-shaped inflation-RPV nexus. The null hypothesis $a=0$ is rejected at the $1 \%$ significance level. Thus, in line with Hypothesis 1, the estimated relationship between inflation and price dispersion is asymmetrically Vshaped around a positive vertex. The estimated vertex, $\widehat{a}=0.0025$, implies that the optimal annual inflation rate for the EU-27 economy should be about 3\% . 
Table 1: Inflation and Relative Price Variability in the European Union: An empirical test of the Head and Kumar monetary search model

\begin{tabular}{|c|c|c|}
\hline & \multicolumn{2}{|c|}{$\begin{array}{c}R P V_{i t}=\alpha_{i}+\lambda_{t}+\beta_{1}\left|\pi_{i t}^{e}\right|+\beta_{2}\left|\left(\pi_{i t}-\pi_{i t}^{e}\right)\right| \\
+\beta_{3}\left|\Pi_{t}^{e}-a\right|+\beta_{4} D_{t}\left|\Pi_{t}^{e}-a\right|+\epsilon_{i t}\end{array}$} \\
\hline & $E U-27$ & Euro-area \\
\hline$\widehat{\beta}_{1}$ & $\begin{array}{l}1.616^{* *} \\
(0.183)\end{array}$ & $\begin{array}{l}0.333^{* *} \\
(0.022)\end{array}$ \\
\hline$\widehat{\beta}_{2}$ & $\begin{array}{l}0.560^{* *} \\
(0.041)\end{array}$ & $\begin{array}{l}0.283^{* *} \\
(0.004)\end{array}$ \\
\hline$\widehat{\beta}_{3}$ & $\begin{array}{l}0.343^{* *} \\
(0.082)\end{array}$ & $\begin{array}{l}0.023 \\
(0.029)\end{array}$ \\
\hline$\widehat{\beta}_{4}$ & $\begin{array}{l}0.543^{* *} \\
(0.251)\end{array}$ & $\begin{array}{l}0.132 \\
(0.131)\end{array}$ \\
\hline$\widehat{a}$ & 0.00250 & 0 \\
\hline$H_{0}: a=0$ & $\begin{array}{c}7.891 \\
{[0.00]}\end{array}$ & - \\
\hline Obs & 1632 & 1632 \\
\hline Product Groups & 12 & 12 \\
\hline Countries & 27 & 12 \\
\hline
\end{tabular}

Notes: Expected and unexpected inflation series are based on an AR forecast model (see Section 3.1). Heteroskedasticity-consistent standard errors in parentheses, $\mathrm{p}$ values in brackets. $D_{t}$ is a dummy variable equal to 1 when $\Pi_{t}^{e}<a$ and zero otherwise. ${ }^{*}, * *$ indicate significance at the $5 \%$ and $1 \%$ significance level. Following Hansen (1999), a bootstrap procedure was used to obtain $p$-values for testing $H_{0}$ : a $=0$. Sample: 05/1997-08/2008.

\subsection{Inflation and RPV in a Highly Integrated Market}

The second column of Table 1 presents the estimation results for the Euro-area panel, a textbook example for a highly integrated market. According to Hypothesis 2, a flatter, almost negligible, inflation-RPV relationship for the highly integrated Euroarea market is predicted by monetary search theory. In fact, compared to the results obtained for the EU 27 panel, the estimated coefficients of overall inflation, $\widehat{\beta}_{3}=$ 0.023 and $\widehat{\beta}_{4}=0.132$, are substantially smaller and far from being significant. In the 
same vein, the estimated $a$ that determines the vertex of the V-shaped inflation-RPV relationship equals zero in the Euro-area.

\section{Changes in the Level of Market Integration over Time}

The results presented in the previous section indicate the importance of the degree of market integration for the relationship between inflation and price dispersion in Europe. Apparently, there is little room for discussion whether Euro-area countries are more integrated compared to all EU-27 member states. Yet, there might have been changes in the level of European market integration over time. This section accounts for possible variations in the degrees of market integration within a country group by splitting the sample periods according to major political changes.

\subsection{The Effect of the 2004 EU Enlargement}

On the first of May 2004, the European Union saw its biggest enlargement to date when ten countries joined the EU. This may have had significant consequences for market integration within the acceding countries. To analyze the effect of the $2004 \mathrm{EU}$ enlargement on market integration and, thereby, on the relationship between inflation and price dispersion, we introduce a new country panel, called acc-2004, which includes all countries involved in the 2004 EU enlargement. Thus, acc-2004 consists of Czech Republic, Estonia, Cyprus, Latvia, Lithuania, Hungary, Malta, Poland, Slovenia, and Slovakia. Since the accession of those countries into the EU single market should have significantly fostered market integration, the effect of inflation on price dispersion should have decreased accordingly.

The results for the pre- and post-05/2004 regressions of the acceding countries panel are shown in Table 2. Again, in line with menu cost and misperception models the impact of expected and unexpected product specific inflation is highly significant. This holds for the pre- and post-2004 period. However, there are striking differences with 
Table 2: Inflation and Relative Price Variability:

The EU enlargement in 2004

\begin{tabular}{c|cc}
\hline \hline & $R P V_{i t}=\alpha_{i}+\lambda_{t}+\beta_{1}\left|\pi_{i t}^{e}\right|+\beta_{2}\left|\left(\pi_{i t}-\pi_{i t}^{e}\right)\right|$ \\
& $+\beta_{3}\left|\Pi_{t}^{e}-a\right|+\beta_{4} D_{t}\left|\Pi_{t}^{e}-a\right|+\epsilon_{i t}$ \\
& $05 / 1997-04 / 2004$ & $05 / 2004-08 / 2008$ \\
\hline \hline$\widehat{\beta}_{1}$ & $1.104^{* *}$ & $0.327^{*}$ \\
$\widehat{\beta}_{2}$ & $(0.146)$ & $(0.148)$ \\
$\widehat{\beta}_{3}$ & $0.458^{* *}$ & $0.262^{* *}$ \\
$\widehat{\beta}_{4}$ & $0.157)$ & $(0.016)$ \\
$\widehat{a}^{*}$ & $0.341^{* *}$ & 0.154 \\
& $0.102)$ & $(0.116)$ \\
$H_{0}: a=0$ & $0.308^{* *}$ & 0.226 \\
& $(0.078)$ & $(0.334)$ \\
Obs & 0.00575 & 0.00335 \\
Product Groups & 7.363 & 0.759 \\
Countries & {$[0.01]$} & {$[0.53]$} \\
\hline \hline
\end{tabular}

Notes: Estimation results are based on acceding countries only. See Table 1 for further explanations.

respect to overall expected inflation. In line with Hypothesis 1, we find evidence of a significant asymmetric V-shaped relation between overall expected inflation and RPV in the pre-2004 regression. The estimated optimal inflation rate is close to $6.9 \%$ in annual terms which clearly exceeds the optimal inflation rate estimated for the complete panel of 27 EU countries. 11

In line with expectations, the results indicate that the effect of inflation on price dispersion has actually decreased during the post-2004 period. The estimated slope coefficients are both smaller $\widehat{\beta}_{3}=0.154<0.341$ and $\widehat{\beta}_{4}=0.226<0.308$ than their

\footnotetext{
${ }^{11}$ Higher optimal inflation rates in the acceding countries group which primarily consists of less developed Central and Eastern European countries might be explained by higher productivity growth rates, see e.g. Égert et al. (2003).
} 
pre-2004 counterparts and insignificant. Moreover, the null hypothesis $a=0$ can not be rejected for the post-2004 period. Therefore, the V-shaped inflation-RPV relationship got flatter as markets of the EU acceding countries have been more integrated in the post-2004 period. Put differently, the results reflect that the EU-enlargement did improve market integration in the acceding countries in a significant way.

\subsection{The Introduction of the Euro}

Within the Euro-area group, the introduction of the Euro might have influenced market integration and, thus, the real effects of inflation. In this Section, we will analyze if the common currency had a significant impact on the relationship between inflation and price dispersion. In monetary search models search costs are certainly more affected by all price quotes given in a common currency instead of a currency in nonphysical form where price comparisons come at the cost of using fixed exchange rates. Therefore, we split the sample period into the pre-Euro part (05/1997-12/2001) and the post-Euro part (01/2002-08/2008).

Table 3 indicates that the introduction of the Euro in 2002 had no impact on the relationship between inflation and RPV. While the effects of expected and unexpected product specific inflation are significant different from zero, overall expected inflation has no impact on price dispersion. In accordance with Table 1, this holds for both, the pre- and post-Euro samples. Similarly, the shift of the V-shaped inflation-RPV nexus is not statistically different from zero in both sub-samples. Even before the Euro was introduced no significant $\mathrm{V}$-shaped relationship can be found. These results are in line with Engel and Rogers (2004) and Parsley and Wei (2008) who find no evidence for a significant change in the integration of Eurozone consumer markets after the introduction of the Euro. They conclude that market integration in Europe occurred already throughout the decade of the 1990s. 
Table 3: Inflation and Relative Price Variability:

The Introduction of the Euro

\begin{tabular}{c|cc}
\hline \hline & & \\
& $R P V_{i t}=\alpha_{i}+\lambda_{t}+\beta_{1}\left|\pi_{i t}^{e}\right|+\beta_{2}\left|\left(\pi_{i t}-\pi_{i t}^{e}\right)\right|$ \\
& $+\beta_{3}\left|\Pi_{t}^{e}-a\right|+\beta_{4} D_{t}\left|\Pi_{t}^{e}-a\right|+\epsilon_{i t}$ \\
& $05 / 1997-12 / 2001$ & $01 / 2002-08 / 2008$ \\
\hline \hline$\widehat{\beta}_{1}$ & $0.175^{* *}$ & $0.382^{* *}$ \\
$\widehat{\beta}_{2}$ & $(0.040)$ & $(0.029)$ \\
$\widehat{\beta}_{3}$ & $0.139^{* *}$ & $0.280^{* *}$ \\
$\widehat{\beta}_{4}$ & $0.028)$ & $(0.051)$ \\
$\widehat{a}$ & 0.155 & 0.066 \\
& -0.531 & $(0.058)$ \\
$H_{0}: a=0$ & $(0.900)$ & 0.193 \\
& 0.0015 & $0.161)$ \\
Obs & 1.691 & 0.001 \\
Product Groups & {$[0.24]$} & 1.425 \\
Countries & 672 & {$[0.31]$} \\
\hline \hline
\end{tabular}

Notes: Estimation results are based on Euro-area countries only. See Table 1 for further explanations.

\section{Concluding Remarks}

In contrast to classical menu-cost or misperception models, the recent literature predicts that the relationship between inflation and the variability of relative prices is non-linear. Advancing on Head and Kumar (2005), we show that the impact of inflation on price dispersion and welfare crucially depends on the level of search costs. In particular, two testable implications of the model are derived: First, the relationship between inflation and price dispersion is predicted to be asymmetrically V-shaped. Second, for decreasing search costs the V-shaped relationship gets progressively flatter. We use monthly HICP-data of a panel of $27 \mathrm{EU}$ countries to test the empirical 
content of both predictions. Assuming that search costs should be negatively related to the level of market integration, the inflation-RPV nexus is estimated for two subgroups of EU countries, i.e. the highly integrated Euro-area and the less integrated EU 27 economy.

Our empirical results confirm both theoretical predictions for the role of inflation regarding different levels of market integration. On the one hand, the relation between RPV and HICP inflation is V-shaped for the less integrated EU27 market, where the vertex occurs at positive values of inflation. On the other hand, we find that the impact of inflation on RPV gets negligible for the highly integrated markets of the Euro-area. These results proved to be robust with respect to alternative splits of the sample, accounting for a particular role of acceding countries in the EU enlargement of 2004 and the introduction of the Euro as a physical currency.

The relationship between inflation and relative price variability has important implications for the welfare cost of inflation. While the earlier literature typically predicts a monotonically increasing effect of inflation on price dispersion, recent evidence suggests that the relationship is actually V-shaped implying e.g. a positive optimal rate of inflation. Yet, the economics behind the non-linearity are still unclear. Choi (2010), for example, shows that a V-shaped relationship between inflation and relative price variability can be generated in a Calvo model of sticky prices with heterogenous sectors. Provided that price rigidity varies with trend inflation, this approach may even explain a time-varying pattern of the inflation-RPV nexus. The current paper shows that similar results can be obtained from monetary search theory shedding new light on the role of market integration on the welfare cost of inflation. 


\section{References}

Barro, Robert J. 1976. Rational Expectations and the Role of Monetary Policy. Journal of Monetary Economics 2:1-32.

Becker, Sascha S. and Dieter Nautz. 2009. Inflation and Relative Price Variability: New Evidence for the United States. Southern Economic Journal 76:146-64.

Bick, Alexander and Dieter Nautz. 2008. Inflation Thresholds and Relative Price Variability: Evidence from U.S. Cities. International Journal of Central Banking 4:61-76.

Burdett, Kenneth and Kenneth L. Judd. Equilibrium Price Dispersion. Econometrica 51:955-969. Caglayan, Mustafa, Alpay Filiztekin and Michael T. Rauh. 2008. Inflation, price dispersion, and market structure. European Economic Review 52:1187-1208.

Choi, Chi-Young. 2010. Reconsidering the Relationship between Inflation and Relative Price Variability. Journal of Money, Credit and Banking, forthcoming.

Craig, Ben and Guillaume Rocheteau. 2008. Inflation and Welfare: A Search Approach. Journal of Money, Credit and Banking 40:89-119.

Debelle, Guy and Owen Lamont. 1997. Relative Price Variability and Inflation: Evidence from US Cities. Journal of Political Economy 105: 132-52.

Égert, Balázs, Imed Drine, Kirsten Lommatzsch and Christophe Rault. 2003. The BalassaSamuelson effect in Central and Eastern Europe: myth or reality? Journal of Comparative Economics 31:552-72.

Elliott, Graham and Allan Timmermann. 2008. Economic Forecasting. Journal of Economic Literature 46:3-56.

Engel, Charles and John H. Rogers. 2004. European market integration after the Euro. Economic Policy 19:347-84.

Fielding, David and Paul Mizen. 2000. Relative Price Variability and Inflation in Europe. Economica 67:57-78.

Fielding, David and Paul Mizen. 2008. Evidence on the Functional Relationship Between Relative Price Variability and Inflation with Implications for Monetary Policy. Economica 75:683-99.

Gali, Jordi, Mark Gertler, and J. David Lopez-Salido. 2001. European Inflation Dynamics. European Economic Review 45:1237-70.

Hansen, Bruce E. 1999. Threshold Effects in Non-Dynamic Panels: Estimation, Testing, and Inference. Journal of Econometrics 93:345-68.

Head, Allen and Alok Kumar. 2005. Price Dispersion, Inflation, and Welfare. International Economic Review 46:533-72.

Head, Allen, Alok Kumar and Beverly Lapham. 2010. Market Power, Price Adjustment, and Inflation. International Economic Review, forthcoming.

Jaramillo, Carlos F. 1999. Inflation and Relative Price Variability: Reinstating Parks' Results. Journal of Money, Credit and Banking 31: 375-85.

Lach, Saul and Daniel Tsiddon. 1992 The Behavior of Prices and Inflation: An Empirical Analysis of Disaggregated Price Data. Journal of Political Economy 100:349-89.

Lucas, Robert. 2000. Inflation and Welfare. Econometrica 68:247-74.

Parsley, David C. 1996. Inflation and Relative Price Variability in the Short and Long Run: New Evidence from the United States. Journal of Money, Credit and Banking 28:323-41. 
Parsley, David and Shang-Jin Wei. 2008. In search of a euro effect: Big lessons from a Big Mac Meal? Journal of International Money and Finance 27:260-76.

Peterson, Brian and Shouyong Shi. 2004. Money, price dispersion and welfare. Economic Theory 24:907-32.

Reinsdorf, Marshall. 1994. New Evidence on the Relation Between Inflation and Price Dispersion. American Economic Review 84:720-31.

Rotemberg, Julio. 1983. Aggregate Consequences of Fixed Costs of Price Adjustment. American Economic Review 73:433-63. 


\section{Appendix}

\section{A1 The Monetary Search Model}

\section{A1.1 Basic Model Setup}

The Head and Kumar (2005) monetary search economy consists of $H \geq 3$ different types of households, with a continuum of identical sellers and buyers in each household and a continuum of identical households in each type. A type $h$ household produces good $\mathrm{h}$ and derives utility only from consumption of good $h+1$, modulo $H$. Exchange is facilitated by the existence of fiat money. At the beginning of each period households receive a lump-sum transfer of new units of fiat money from the government that has no other purpose than to increase the stock of money at gross rate $\gamma$. Members of a representative type $h$ who are sellers produce good $h$ at marginal costs $\phi$. In contrast, buyers of this representative household observe random number of price quotes and may purchase good $h+1$ at the lowest price observed. Let $q_{k t}$ denote the measure of the household's buyers who observe $k \in\{1,2, \ldots ., K\}$ price quotes in period $t$. For each price quote observed, the household pays a search cost of $\mu$ units. Thus, household's total disutility of search in period $t$ is equal to $\mu \sum_{k=1}^{K} k q_{k t}{ }^{12}$ Overall, a representative household maximizes the expected discounted sum of utility from consumption minus total production and search costs over an infinite horizon:

$$
U=E_{0}\left\{\sum_{t=0}^{\infty} \beta^{t}\left[\left(u\left(c_{t}\right)-\phi y_{t}-\mu\left(2-q_{t}\right)\right]\right\},\right.
$$

where $\beta$ is a discount factor, $c_{t}$ is consumption of the preferred good in time period $t$ and $y_{t}$ is total production in period $t$.

Restricting the analysis to symmetric and stationary monetary equilibria (SME's), buyers' reservation levels are endogenous and depend on the marginal value of fiat money.

\footnotetext{
12 Without loss of generality, we will assume in the following that $K=2$ (see also Head and Kumar, 2005, Corollary 2). This causes buyers to observe either one price quote with probability $q_{t}$ or two prices with probability $1-q_{t}$. Hence, total search costs in period $t$ are equal to $\mu\left(2-q_{t}\right)$.
} 
Furthermore, all households choose the same probability for their buyers to observe different numbers of price quotes, the same distribution of posted prices, and all have the same consumption, money holdings, and valuation of money. It is also important to note that if the SME is characterized by some buyers observing one price while others observe two, then the distribution of prices will exhibit price dispersion necessarily (Head and Kumar, 2005, p. 542). Moreover, in this model the relationship between inflation and RPV is determined by two opposing effects resulting in an asymmetrically V-shaped inflation-RPV nexus (see Section 2) ${ }^{13}$

\section{A1.2 The Importance of Search Costs}

According to Head and Kumar (2005) and Head et al. (2010) the household's optimal choice of $q$ is given by

$$
q^{*}= \begin{cases}0 & \text { if } \mu<\mu_{L} \equiv u^{\prime}\left(c_{2}\right)\left[c_{2}-c_{1}\right] \\ \frac{\left[u^{\prime}-1\left(\frac{\mu}{c_{2}-c_{1}}\right)-c_{2}\right]}{c_{1}-c_{2}} & \text { if } \mu_{L} \leq \mu \leq \mu_{H} \\ 1 & \text { if } \mu>\mu_{H} \equiv u^{\prime}\left(c_{1}\right)\left[c_{2}-c_{1}\right]\end{cases}
$$

where $c_{1}$ and $c_{2}$ are the expected purchases of buyers observing one and two price quotes, respectively, and $\mu_{L}$ and $\mu_{H}$ are state contingent cut-off levels for search costs. Equation (4) illustrates the importance of search costs for the household's search strategy and ultimately for the existence of an equilibrium with price dispersion. More specifically, an SME with price dispersion only exists if search costs lie in a certain interval $\left(\mu_{L} \leq \mu \leq \mu_{H}\right)$. When search costs fall below a critical threshold value $\left(\mu<\mu_{L}\right)$, the household behaves optimally by setting the probability of observing only one price quote equal to zero. In this scenario, sellers' market power erodes, the price distribution is concentrated around the marginal cost price and the real effects of inflation vanish. Furthermore, with very high search costs $\left(\mu>\mu_{H}\right)$ the household has no incentive to have any of its buyers observe a second price quote, $q^{*}=1$. Here, the sellers' act as monopolists and the price is equal to the buyer's reservation level.

\footnotetext{
${ }^{13}$ Head et al. (2010) study the extend to which real and nominal prices adjust to fluctuations in productivity and the money growth rate in a similar but stochastic environment.
} 


\section{A1.3 Results from a Simulation Study}

Following Gali et al. (2001), Head and Kumar (2005), and Head et al. (2010), we use a $\log$ utility function and set the discount factor, $\beta$, equal to 0.9 . To achieve an average mark-up of prices over marginal costs of $10 \%$, we set $\phi=0.1$ and $\mu=0.029$. Furthermore, we allow $\gamma$, which determines the growth rate of the money stock and the rate of inflation to range between 1 and 1.5. The solid line in Figure 1 and the upper graph of Figure 2 depict the V-shaped relationship between inflation and price dispersion for this benchmark scenario.

The middle and lower graph in Figure 2 demonstrate how lower search costs affect the inflation-RPV nexus. Compared to the benchmark simulation search costs are set equal to 0.024 (mark-up $=5.2 \%$ ) and 0.019 (mark-up $=3.1 \%$ ), respectively, which causes the inflation-RPV relationship to get progressively flatter. Decreasing the level of search cots even further $(\mu \leq 0.011)$ results in a breakdown of the nonlinear inflation-RPV linkage. In this case, price dispersion equals zero for any level of inflation.

In line with Head and Kumar (2005), for a high search cost market RPV is V-shaped in expected overall inflation with the vertex occurring at positive levels of the inflation measure. The level of search costs determines the curvature of the inflation-RPV nexus. With lower search costs, price dispersion responds less to inflation. In the limiting case, if search cost fall below a certain threshold value, the real effects of inflation on RPV vanish and the classical dichotomy holds. 


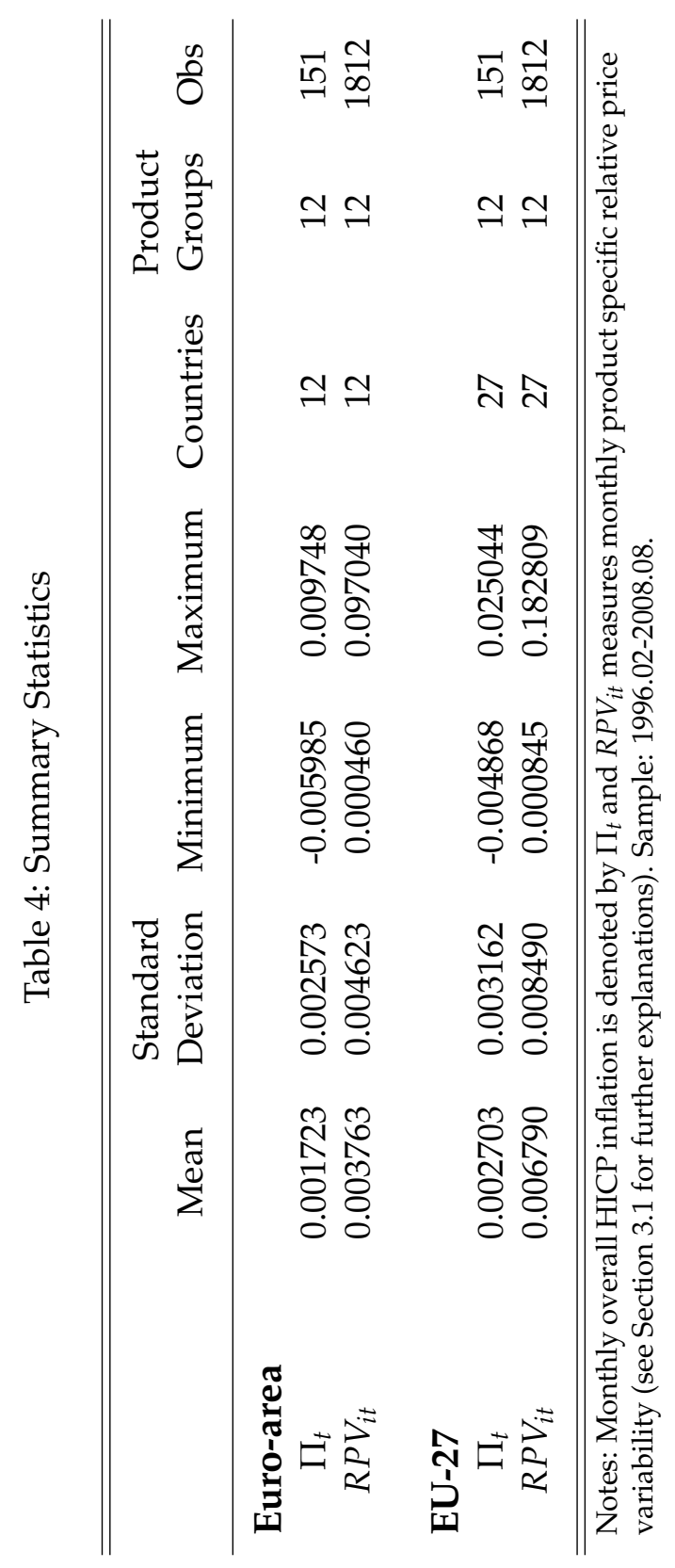


Figure 3: Product specific inflation and RPV (Euro-area)

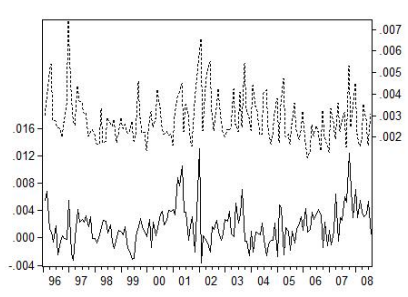

(a) $\mathrm{CP} 01$

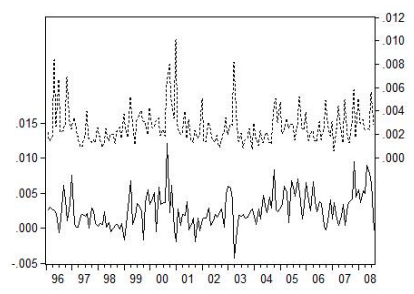

(d) $\mathrm{CP} 04$

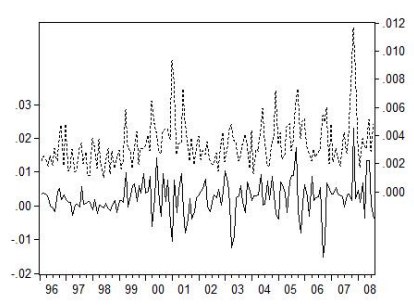

(g) $\mathrm{CP} 07$



(j) $\mathrm{CP} 10$

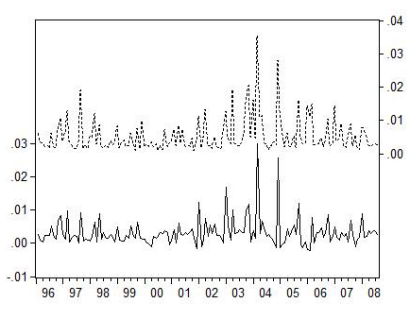

(b) $\mathrm{CP} 02$

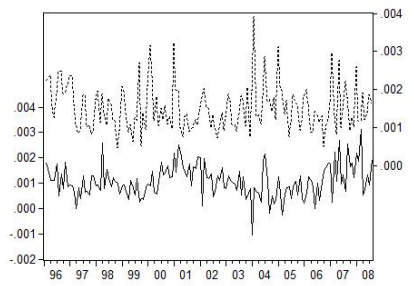

(e) $\mathrm{CP} 05$

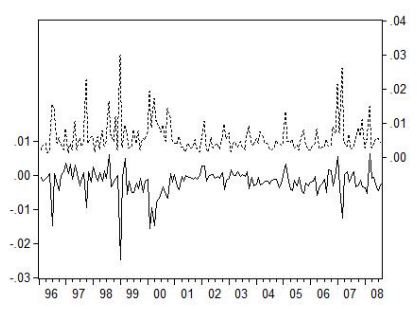

(h) $\mathrm{CP} 08$

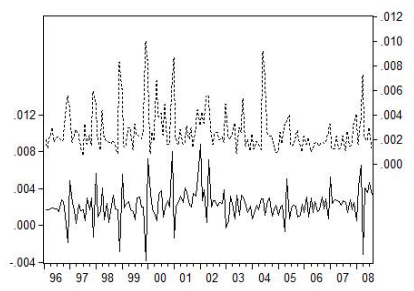

(k) CP11

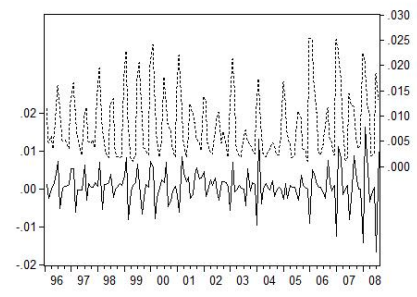

(c) $\mathrm{CP} 03$

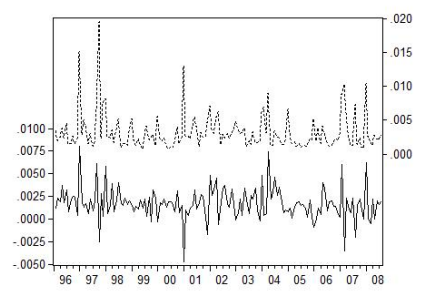

(f) $\mathrm{CP} 06$

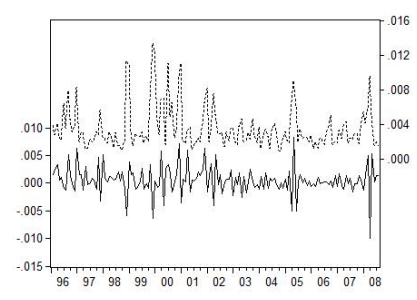

(i) $\mathrm{CP} 09$

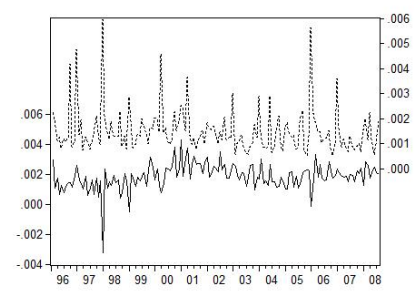

(l) $\mathrm{CP} 12$

Notes: Monthly HICP product specific inflation rates (left scale). Monthly product specific RPV (right scale). 1996.02-2008.08. 
Figure 4: Product specific inflation and RPV (EU-27)

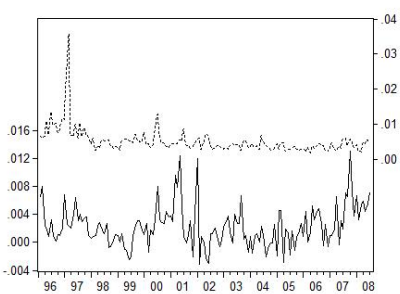

(a) $\mathrm{CP} 01$

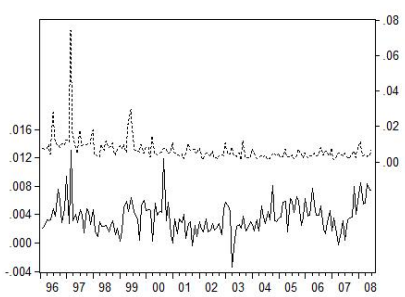

(d) $\mathrm{CP} 04$

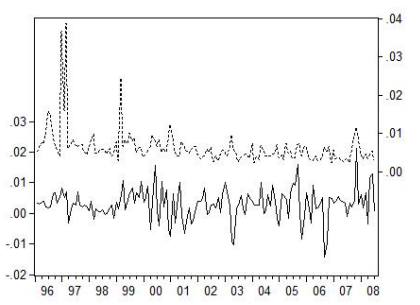

(g) $\mathrm{CP} 07$

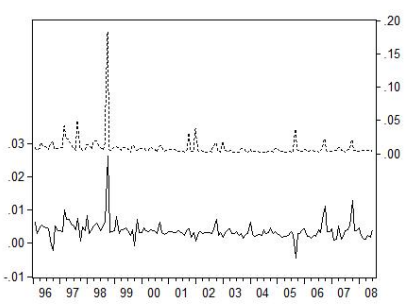

(j) $\mathrm{CP} 10$

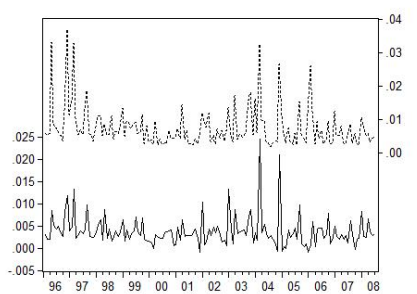

(b) $\mathrm{CP} 02$

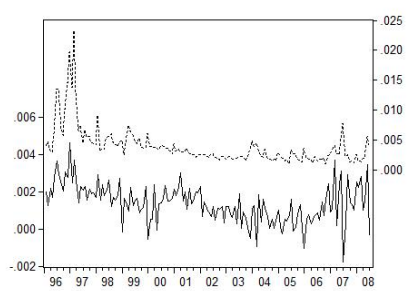

(e) $\mathrm{CP} 05$

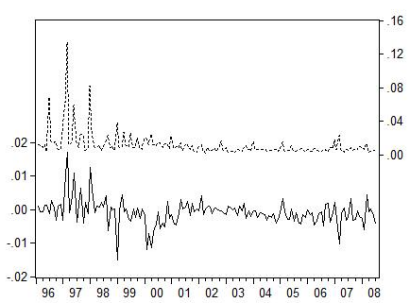

(h) $\mathrm{CP} 08$

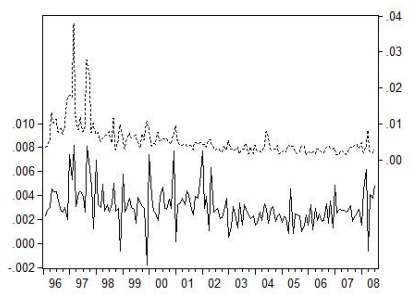

(k) $\mathrm{CP} 11$

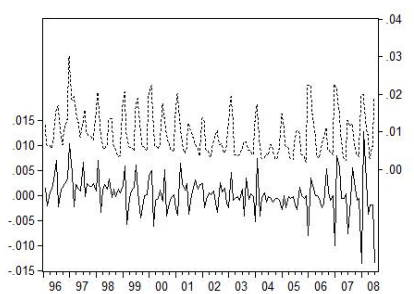

(c) $\mathrm{CP} 03$

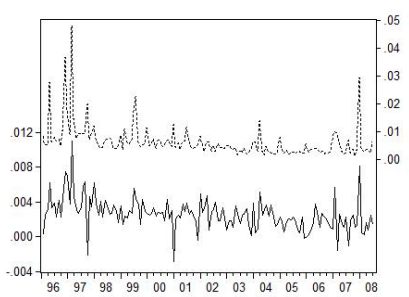

(f) $\mathrm{CP06}$

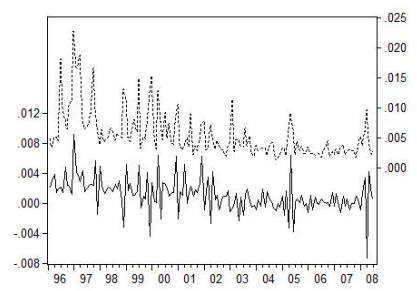

(i) $\mathrm{CP} 09$

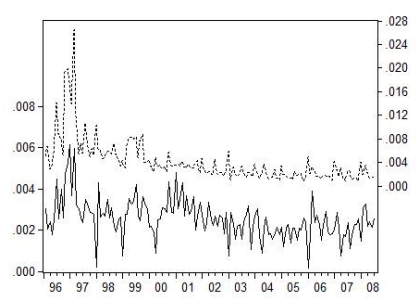

(l) $\mathrm{CP} 12$

Notes: Monthly HICP product specific inflation rates (left scale). Monthly product specific RPV (right scale). 1996.02-2008.08. 


\section{SFB 649 Discussion Paper Series 2010}

For a complete list of Discussion Papers published by the SFB 649, please visit http://sfb649.wiwi.hu-berlin.de.

001 "Volatility Investing with Variance Swaps" by Wolfgang Karl Härdle and Elena Silyakova, January 2010.

002 "Partial Linear Quantile Regression and Bootstrap Confidence Bands" by Wolfgang Karl Härdle, Ya'acov Ritov and Song Song, January 2010.

003 "Uniform confidence bands for pricing kernels" by Wolfgang Karl Härdle, Yarema Okhrin and Weining Wang, January 2010.

004 "Bayesian Inference in a Stochastic Volatility Nelson-Siegel Model" by Nikolaus Hautsch and Fuyu Yang, January 2010.

005 "The Impact of Macroeconomic News on Quote Adjustments, Noise, and Informational Volatility" by Nikolaus Hautsch, Dieter Hess and David Veredas, January 2010.

006 "Bayesian Estimation and Model Selection in the Generalised Stochastic Unit Root Model" by Fuyu Yang and Roberto Leon-Gonzalez, January 2010.

007 "Two-sided Certification: The market for Rating Agencies" by Erik R. Fasten and Dirk Hofmann, January 2010.

008 "Characterising Equilibrium Selection in Global Games with Strategic Complementarities" by Christian Basteck, Tijmen R. Daniels and Frank Heinemann, January 2010.

009 "Predicting extreme VaR: Nonparametric quantile regression with refinements from extreme value theory" by Julia Schaumburg, February 2010.

010 "On Securitization, Market Completion and Equilibrium Risk Transfer" by Ulrich Horst, Traian A. Pirvu and Gonçalo Dos Reis, February 2010.

011 "Illiquidity and Derivative Valuation" by Ulrich Horst and Felix Naujokat, February 2010.

012 "Dynamic Systems of Social Interactions" by Ulrich Horst, February 2010.

013 "The dynamics of hourly electricity prices" by Wolfgang Karl Härdle and Stefan Trück, February 2010.

014 "Crisis? What Crisis? Currency vs. Banking in the Financial Crisis of 1931" by Albrecht Ritschl and Samad Sarferaz, February 2010.

015 "Estimation of the characteristics of a Lévy process observed at arbitrary frequency" by Johanna Kappusl and Markus Reiß, February 2010.

016 "Honey, I'll Be Working Late Tonight. The Effect of Individual Work Routines on Leisure Time Synchronization of Couples" by Juliane Scheffel, February 2010.

017 "The Impact of ICT Investments on the Relative Demand for HighMedium-, and Low-Skilled Workers: Industry versus Country Analysis" by Dorothee Schneider, February 2010.

018 "Time varying Hierarchical Archimedean Copulae" by Wolfgang Karl Härdle, Ostap Okhrin and Yarema Okhrin, February 2010.

019 "Monetary Transmission Right from the Start: The (Dis)Connection Between the Money Market and the ECB's Main Refinancing Rates" by Puriya Abbassi and Dieter Nautz, March 2010.

020 "Aggregate Hazard Function in Price-Setting: A Bayesian Analysis Using Macro Data" by Fang Yao, March 2010.

021 "Nonparametric Estimation of Risk-Neutral Densities" by Maria Grith, Wolfgang Karl Härdle and Melanie Schienle, March 2010. 


\section{SFB 649 Discussion Paper Series 2010}

For a complete list of Discussion Papers published by the SFB 649, please visit http://sfb649.wiwi.hu-berlin.de.

022 "Fitting high-dimensional Copulae to Data" by Ostap Okhrin, April 2010.

023 "The (In)stability of Money Demand in the Euro Area: Lessons from a Cross-Country Analysis" by Dieter Nautz and Ulrike Rondorf, April 2010.

024 "The optimal industry structure in a vertically related market" by Raffaele Fiocco, April 2010.

025 "Herding of Institutional Traders" by Stephanie Kremer, April 2010.

026 "Non-Gaussian Component Analysis: New Ideas, New Proofs, New Applications" by Vladimir Panov, May 2010.

027 "Liquidity and Capital Requirements and the Probability of Bank Failure" by Philipp Johann König, May 2010.

028 "Social Relationships and Trust" by Christine Binzel and Dietmar Fehr, May 2010.

029 "Adaptive Interest Rate Modelling" by Mengmeng Guo and Wolfgang Karl Härdle, May 2010.

030 "Can the New Keynesian Phillips Curve Explain Inflation Gap Persistence?" by Fang Yao, June 2010.

031 "Modeling Asset Prices" by James E. Gentle and Wolfgang Karl Härdle, June 2010.

032 "Learning Machines Supporting Bankruptcy Prediction" by Wolfgang Karl Härdle, Rouslan Moro and Linda Hoffmann, June 2010.

033 "Sensitivity of risk measures with respect to the normal approximation of total claim distributions" by Volker Krätschmer and Henryk Zähle, June 2010.

034 "Sociodemographic, Economic, and Psychological Drivers of the Demand for Life Insurance: Evidence from the German Retirement Income Act" by Carolin Hecht and Katja Hanewald, July 2010.

035 "Efficiency and Equilibria in Games of Optimal Derivative Design" by Ulrich Horst and Santiago Moreno-Bromberg, July 2010.

036 "Why Do Financial Market Experts Misperceive Future Monetary Policy Decisions?" by Sandra Schmidt and Dieter Nautz, July 2010.

037 "Dynamical systems forced by shot noise as a new paradigm in the interest rate modeling" by Alexander L. Baranovski, July 2010.

038 "Pre-Averaging Based Estimation of Quadratic Variation in the Presence of Noise and Jumps: Theory, Implementation, and Empirical Evidence" by Nikolaus Hautsch and Mark Podolskij, July 2010.

039 "High Dimensional Nonstationary Time Series Modelling with Generalized Dynamic Semiparametric Factor Model" by Song Song, Wolfgang K. Härdle, and Ya'acov Ritov, July 2010.

040 "Stochastic Mortality, Subjective Survival Expectations, and Individual Saving Behavior" by Thomas Post and Katja Hanewald, July 2010.

041 "Prognose mit nichtparametrischen Verfahren" by Wolfgang Karl Härdle, Rainer Schulz, and Weining Wang, August 2010.

042 "Payroll Taxes, Social Insurance and Business Cycles" by Michael $C$. Burda and Mark Weder, August 2010.

043 "Meteorological forecasts and the pricing of weather derivatives" by Matthias Ritter, Oliver Mußhoff, and Martin Odening, September 2010.

044 "The High Sensitivity of Employment to Agency Costs: The Relevance of Wage Rigidity" by Atanas Hristov, September 2010.

045 "Parametric estimation of risk neutral density functions" by Maria Grith and Volker Krätschmer, September 2010. 


\section{SFB 649 Discussion Paper Series 2010}

For a complete list of Discussion Papers published by the SFB 649, please visit http://sfb649.wiwi.hu-berlin.de.

046 "Mandatory IFRS adoption and accounting comparability" by Stefano Cascino and Joachim Gassen, October 2010.

047 "FX Smile in the Heston Model" by Agnieszka Janek, Tino Kluge, Rafał Weron, and Uwe Wystup, October 2010.

048 "Building Loss Models" by Krzysztof Burnecki, Joanna Janczura, and Rafał Weron, October 2010.

049 "Models for Heavy-tailed Asset Returns" by Szymon Borak, Adam Misiorek, and Rafał Weron, October 2010.

050 "Estimation of the signal subspace without estimation of the inverse covariance matrix" by Vladimir Panov, October 2010.

051 "Executive Compensation Regulation and the Dynamics of the PayPerformance Sensitivity" by Ralf Sabiwalsky, October 2010.

052 "Central limit theorems for law-invariant coherent risk measures" by Denis Belomestny and Volker Krätschmer, October 2010.

053 "Systemic Weather Risk and Crop Insurance: The Case of China" by Wei Xu, Ostap Okhrin, Martin Odening, and Ji Cao, October 2010.

054 "Spatial Dependencies in German Matching Functions" by Franziska Schulze, November 2010.

055 "Capturing the Zero: A New Class of Zero-Augmented Distributions and Multiplicative Error Processes" by Nikolaus Hautsch, Peter Malec and Melanie Schienle, November 2010.

056 "Context Effects as Customer Reaction on Delisting of Brands" by Nicole Wiebach and Lutz Hildebrandt, November 2010.

057 "Consumption Growth and Volatility with Consumption Externalities" by Runli Xie, November 2010.

058 "Inflation, Price Dispersion and Market Integration through the Lens of a Monetary Search Model" by Sascha S. Becker and Dieter Nautz, November 2010. 